\title{
MEMÓRIA SOCIAL, EDUCAÇÃO E SOCIALIZAÇÃO DE GÊNERO: MARCOS A PARTIR DE UM GRUPO DE MULHERES RURAIS
}

\author{
Pâmela Pitágoras Freitas Lima Ferrarini ${ }^{1}$ \\ Lívia Diana Rocha Magalhães ${ }^{2}$
}

\begin{abstract}
RESUMO
È objetivo deste trabalho analisar a memória social, sob uma perspectiva de gênero,de dez mães trabalhadoras rurais, com idade entre 20 e 74 anos, de um município baiano. A técnica utilizada para coleta de dados foi a de grupos focais, que consiste em realizar encontros que favoreçam a interação grupal ao se discutir uma temática específica. Pode-se observar que as referências ao passado vivido é evocado por essas mulheres para falar das preocupações atuais com a educação de seus filhos, resgatando como referência comparativa o acesso precário a escola em suas infâncias, com a garantia de educação de suas proles. Entretanto, essas mulheres evocam, a partir de uma leitura de socialização de gênero, que a educação recebida em suas casas foi de qualidade, apesar no não acesso a uma educação formal e lamentam terem dificuldade em educar seus filhos com os parâmetros de outrora.

Palavras-chave: Psicologia Social; Gênero; Memória Social.
\end{abstract}

\section{SOCIAL MEMORY, EDUCATION AND GENDER SOCIALIZATION: LIMIT FROM A GROUP OF RURAL WOMEN}

\begin{abstract}
It is the aim of this work is to analyze social memory in the gender perspective of ten rural working mothers, aged between 20 and 74 years, a municipality of Bahia. Data collection was made through the focus groups, which is to conduct meetings that encourage group interaction when discussing a specific topic. It can be observed that the references to the past is evoked lived by these women to speak of current concerns with the education of their children, rescuing as comparative reference poor access to school in their childhood, ensuring education of their offspring. However, these women evoke, from a reading of gender socialization, that the education received at home was quality, despite the lack of access to formal education and regret having difficulty in educating their children with the parameters of yore.
\end{abstract}

Keyword: Social Psychology, Gender, Social Memory.

Avaliando o desenvolvimento histórico da família, da infância e da mulher, identificamos que há um processo de socialização diferenciada a partir da perspectiva de gênero. Mesmo com as transformações socioculturais que viabilizaram maior igualdade nas relações familiares e conjugais, acompanhando transformações no papel da mulher na família e na sociedade, ainda é difícil romper com valores tradicionais, que insistem em ver o casamento e a constituição de família como as principais metas "femininas", apoiados por discursos religiosos, pedagógicos e psicológicos, favorecendo a manutenção de uma 
socialização de gênero desigual e reprodutiva (COUTINHO \& MENANDRO, 2010). Portanto, passaremos agora a descrever as categorias analíticas eleitas dessa pesquisa, relacionadas com a memória social, que são: mulher, infância e família. Estas são importantes para elucidar sobre os elementos empíricos manifestados pelas participantes da pesquisa.

\title{
1.1 Mulher, família, infância e memória: imbricações no espaço do trabalho rural.
}

Conforme nos aponta Arruda (2002, p. 133), devemos compreender gênero como "uma categoria relacional, na qual, ao se levar em conta os gêneros em presença, também se consideram as relações de poder, a importância da experiência, da subjetividade, do saber concreto". As primeiras propostas de modificação dos estudos sobre a mulher partiu do movimento feminista, ganhando força na década de setenta do século XX. Phillipp (2010) identifica duas fases no campo de investigação de gênero, a partir da perspectiva feminista, uma inicial que foca nos estudos dos textos científicos clássicos e uma segunda, que aborda problemáticas particulares do universo feminino, como a família e as relações de trabalho. Hoje, o campo de estudos de gênero se amplia para uma perspectiva mais inter-relacional, com universo masculino/feminino em diversas amplitudes e como elemento necessário para se compreender as relações sociais de gênero na atualidade.

Nessa perspectiva, mulheres e homens não possuem as mesmas referências ao recordar suas experiências (JELIN, 2002). Dessa forma, pensar a memória também deve se levar em conta a dimensão de gênero. Em suas palavras:

\begin{abstract}
É inevitável dado a sua história social, que mulheres e homens desenvolvem habilidades diferentes no que concerne a sua memória individual, coletiva e social. Na medida em que a socialização de gênero implica-se em certos campos sociais e culturais do que em outros e defineidentidades ancoradas em certas atividades mais que outras como trabalho e/ou família, por exemplo. E não é de se estranharum correlato entre práticas sociais e recordações, memória narrada (JELIN, 2002, p. 107, tradução livre ${ }^{1}$ )
\end{abstract}

Em uma direção próxima, Perrot (1989) destaca que é necessário levar em conta que ao se discutir sobre memória feminina, é preciso levar em conta certas especificidades, na medida em que as práticas socioculturais presentes nas operações que constituem a memória estão imbricadas nas relações masculinas/femininas e são produto de uma história, marcadas de forma acentuada por papéis sociais delimitados.

A historiadora inglesa Joan Scott (1996, p. 14) apresentou importantes contribuições aos estudos de gênero quando considera que as sociedades outorgam as diferenças entre os sexos, varia formas de poder que regulam as relações sociais. Para ela o gênero é "um elemento constitutivo de relações sociais fundadas sobre as diferenças percebidas entre os sexos, e o gênero é um primeiro modo de dar significado às relações de poder";

\footnotetext{
${ }^{1}$ No origina em espanhol "La experienciadirecta y laintuiciónindican que mujeresyhombresdesarrollan habilidades diferentes enlo que concierne a la memoria. Em la medida en que lasocialización de gênero implica prestar más atencíon a ciertos campos sociales y culturales que a otros y definir lãs identidades ancladas em ciertasactividades más que em otras (trabajos o família, por ejemplo), es de esperar um correlato em lasprácticasdelrecuerdo y de la memoria narrativa".
} 
Como afirma Zincone (1992) e Bonan (2002), a "representação moderna de gênero está profundamente entrelaçadacom a imaginação institucional dos setores públicos e privados e com a idéia dual desse poder". E desse modo, "o poder do tipo de familia ou a estrututurahierarquicanãosó as relaçõessociais entre os sexos mas sim a através de outrasestruturas das relaçõessociais".

Mas estudar gênero, da perspectiva particularmente do feminino, sem dúvida, requer a atenção de construções sociais que lhe estão associadas, como as relações familiares, a infância, o trabalho e a escola e compreendemos que houve uma progressiva valorização do sentimento da infância desde Séculos XVI e XVII (ARIÈS, 1981) e que esta construção histórica deve ser vista veiculada articulada com a evolução da família e das relações internas entre seus membros, e do papel da escola. Por ser considerado um fenômeno social novo no campo dos estudos científicos, é ainda crescente o número de pesquisas que enfocam a infância na amplitude de suas características, principalmente engendrando nas áreas da Psicologia Social e da Memória. Conforme aponta Nascimento (2004), pesquisas sobre a infância têm tido ainda pouco aprofundamento nos estudos da Memória Social no Brasil.

\subsubsection{A construção social da infância}

A infância enquanto objeto de interesse científico é tema recente na produção de conhecimento. Há muito pouco tempo, as crianças eram consideradas "pequenos adultos", e que, portanto, não possuíam características que as diferenciassem destes. A infância, enquanto etapa do desenvolvimento da vida que compreende peculiaridades, é algo novo no campo da investigação científica (ARIÈS, 1981). Para Casas (1998), a infância é um determinado período da vida, medido por um intervalo de idade; o conjunto da população de dado território; o conjunto de características psicossociobiológicas de alguns sujeitos em desenvolvimento (idade cronológica indicando etapas desse desenvolvimento) e aquilo que as pessoas dizem ser a infância, ou seja, imagens coletivamente partilhadas, que vão evoluindo historicamente. Segundo ainda este autor, compreender a infância de uma perspectiva multidisciplinar é partir dos conhecimentos dos fatores psicossociais que incidem sobre a legitimação das necessidades e problemas sociais da infância, em que "as experiências precoces deixam marcas permanentes no indivíduo; [...] e a socialização e a adaptação integraria o desenvolvimento individual e os objetivos sociais na infância" (CASAS, 1998, p. 62).

A progressiva valorização do sentimento da infância a partir dos Séculos XVI e XVII na Europa (ARIĖS, 1981), a avaliação de que a própria vida merecia ser contada, produziu uma quantidade razoável de estudos que passou a enfocar a infância como campo de investigação. Para o caso do Brasil, esta busca por entender os diversos aspectos da infância brasileira passou a ganhar força a partir da década de 1940 como o momento em que as memórias da infância ganham espaço científico e literário no país (NASCIMENTO, 2004).

Portanto a infância é fruto do seu contexto histórico e deve ser compreendida como produto deste. Segundo Vasen (2008), a compreensão a respeito da infância perpassa por diferentes etapas da construção temporal das sociedades humanas. E esta construção deve ser vista veiculada com a evolução da família e das relações internas entre seus membros, e do papel da escola. Entre os períodos paleolítico e neolítico as crianças eram consideradas meras consequência da procriação, e o exercício dos cuidados maternos e paternos eram 
necessários apenas para a sobrevivência destes. No momento em que a espécie humana desenvolve habilidades e ferramentas que os possibilitassem deixar de ser nômades, surge uma bagagem sociocultural que passa a diferenciar os adultos das crianças não apenas pelos seus tamanhos, mas pelo acúmulo de conhecimento. Neste momento, deu-se início ao processo de transmissão do conhecimento adquirido. Para Vasen (2008), este acúmulo e ensino passaram a contribuir para que as crianças tivessem um status de filhos e não mais de crias; e a linguagem fomentou ainda mais esta diferenciação, já que a transmissão cultural enriquecia os laços entre adultos e crianças.

É na modernidade que nasce a preocupação em se diferenciar a infância com outras etapas da vida. Surgem então objetos de distinção entre idade e sexo, como a arquitetura das moradias, jogos e vestimentas mais adequadas às crianças. A infância moderna adquiriu a atenção institucional dos Estados, da Igreja, da família e daquela criada especificamente para atender a este público, que é a escola. Atualmente, este cenário não é o mesmo, já que a família passou a ocupar um lugar decrescente em relação com outros âmbitos de socialização, formal como a escola, e informal como os meios de comunicação (VASEN, 2008).

\subsubsection{Memória e Infância}

Por ser considerado um fenômeno social novo no campo dos estudos científicos, é ainda crescente o número de pesquisas que enfocam a infância na amplitude de suas características, principalmente engendrando nas áreas da Psicologia Social e da Memória. Conforme aponta Nascimento (2004), pesquisas sobre a infância têm tido ainda pouco aprofundamento nos estudos da Memória Social no Brasil.

Portanto, as memórias da infância são suscetíveis ao ponto de vista do adulto, e, as lembranças da infância só seriam conservadas devido à memória social. Segundo Breda (2010), “[...] as memórias de infância podem ser consideradas memórias de vivências, experiências, ações sociais enquanto atores pertencentes a uma categoria distinta da categoria à qual pertencem nos dias atuais (a idade adulta)".

Entretanto, há outra perspectiva de apontamentos sobre o tema da infância e suas rememorações, denominando, nestes estudos, a categoria de memória da infância. Outra estudiosa que apresenta esta conceituação é a socióloga argentina Sandra Carli. A autora afirma que a memória da infância se fabrica através da escritura adulta, produzindo-se uma particular apropriação do passado. Segundo aponta:

[...] A memória da infância permite, de maneira particular, uma compreensão do passado desde uma dimensão centrada no presente, habilitando o deslocamento entre distintas temporalidades para recuperar um tempo que se escapa. A memória da infância se modela em distintas superfícies culturais (pintura, cinema, literatura autobiográfica, testemunhos, objetos), provocando que uma diversidade de fontes adquiram valor para identificar e analisar os elementos de um tempo histórico e a recriação em etapas posteriores. Desta perspectiva, a pergunta pela infância interroga de forma mais ampla as experiências infantis e os vínculos entre as gerações, a partir da relação com o passado que se 
constrói através dos modos particulares da memória. (CARLI, 2011, p. 23, tradução livre). ${ }^{2}$

Para Halbwachs (2004) afirma que a memória dos adultos sobre a infância não pode ser entendida apenas como uma memória pessoal, mas sim a partir da memória social, que são compartilhadas.

\subsection{Família, gênero e trabalho rural.}

Os modelos mais clássicos de análise das relações de gênero na área rural em geral localizam as mulheres, particularmente na agricultura familiar, e os homens na gestão da unidade familiar, na comercialização dos produtos, etc (CORDEIRO, 2012). Entretanto, para a autora, as relações de gênero na área rural vão além: há também conflitos, tensões, fissuras, além de negociação e barganha por novas posições e lugares entre homens e mulheres.

Esses modelos clássicos também costumam desconsiderar a variedade de modos de organização familiar - que não correspondem, muitas vezes, ao modelo de pai, mãe, filhos e filhas - e as diferentes formas de organização da produção familiar e as implicações que estas infligem nos aspectos socioeconômicos e culturais da família rural. Essa análise se transformou quase num modelo ideal para pensar as relações de gênero na área rural.

Para Sánchez (1995), na atualidade, as famílias se ajustam a um modelo que nascem da consequência de um conjunto de transformações sociais e políticas, e que refletem concretamente em mudanças nas relações entre os membros, que antes tinham papéis bem delimitados e marcados.

Para Jelin (1995), a família não será democrática, principalmente entre os gêneros, enquanto não for democrática nos acessos aos serviços cotidianos domésticos, sendo ainda este de responsabilidade da mulher.

O trabalho doméstico integrou-se ao cotidiano das mulheres, pri9ncipalmente das camadas populares, como ressaltam as autoras Alves e Cunha, (2009, p. 303) “[...] passando a compor o cenário da rotina feminina: a dupla jornada de trabalho, pautada no acúmulo de funções derivadas dos encargos domésticos, do cuidado dos filhos somadas às atividades remuneradas desenvolvidas dentro ou fora de casa".

Dessa forma, descreveremos o contexto socioeconômico e espacial em que residem as mulheres participantes da nossa pesquisa.

\subsection{Os principais dados socioeconômicos das mulheres rurais em estudo}

\footnotetext{
${ }^{2}$ No original em espanhol: “[...] La memoria de la infancia permite, de manera particular, una comprensíon del pasado desde una mirada centrada en el presente, habilitando el desplazamiento entre distintas temporalidades para recuperar um tiempo que se escabulle. La memoria de la infancia se modela en distintas superficies culturales (pintura, cine, literatura autobiográfica, testimonios, objetos), provocando que una diversidad de fuentes adquieran valor para identificar y analizar los elementos de un tiempo histórico y su recreacíon en etapas posteiores. Desde esta perspectiva, la pregunta por la infancia interroga en forma más amplia las experiencias infantiles y los vínculos entre las generaciones, a partir de la relacíon con el pasado que se construye a través de los modos particulares de la memoria”.
} 
As mulheres rurais em estudo tem muitas características em comum. Constatamos que quarto das dez participantes do estudo já habitaram outros municípios e regiões da Bahia, mas a maioria delas nasceu e viveu na região sudoeste do estado. É interessante observar que elas sempre se referem em relação a esse espaço, com a descrição da história da comunidade rural onde vivem e sua origem. Todas seguem o cristianismo, divididas entre o catolicismo e o protestantismo e participam ativamente da associação de moradores e todas elas têm rádio e televisão em suas casas. A maioria recebe algum benefício assistencial, como o "bolsa família"

A densidade residencial é pequena, com média de três pessoas por habitação, demonstrando uma redução dos membros familiares por habitação, uma vez que segundo o IBGE (2010) há um declínio da taxa de fecundidade feminina, em que as famílias brasileiras tende a ter menos filhos em todas as classes sociais.De fato, estes dados são corroborados pelas participantes da pesquisa: a) segundo as mulheres mais velhas (entre 53 a 74 anos), elas têm em média cinco filhos, que hoje não residem na mesma habitação; e b) quando se compara as informações, constata-se que há um declínio da quantidade de filhos para o grupo das mulheres mais jovens, que têm em média entre dois e três filhos, cuja maioria residem com elas por serem crianças ou adolescentes.

Inicialmente ressaltamos que, por meio dos questionários socioeconômicos, ficou evidente que todas as participantes da pesquisa em algum momento de suas vidas, trabalharam como agricultoras, safristas ou diaristas, na roça, no campo. Muitas, inclusive, permanecem executando essa função.

\subsubsection{O trabalho}

As mulheres mais velhas informam que foi na infância, entre a década de $1950 \mathrm{e}$ 1960 do século XX, que iniciaram esta atividade laboral. Já as mulheres mais novas começaram a trabalhar na adolescência, entre as décadas de 90 do século XX e os anos 2000 do século XXI. Boa parte das pesquisadas ainda possui como atividade laboral principal a agricultura. Algumas que já são aposentadas realizam durante a safra do café atividades temporárias na colheita.

Embora o trabalho seja uma categoria importante na análise desse estudo, que aparece como uma constante na vida das participantes da pesquisa, notamos que durante o andamento da pesquisa, este tema se constituiu quase sempre como elemento periférico das mulheres aqui estudadas, e considerarmos este como elementos de coesão de descrição do referido grupo. $\mathrm{O}$ foco central de seus relatos era a escola e o fato de morarem na zona rural, serem mulheres, casarem-se cedo e constituírem família, impedindo-as de ter acesso à escola.

\subsection{Metodologia}

\footnotetext{
${ }^{3} \mathrm{O}$ Bolsa Família (PBF) é um programa de transferência direta de renda que beneficia famílias em situação de pobreza e de extrema pobreza em todo o País e integra o Plano Brasil Sem Miséria (BSM). Para maiores informações, consultar Brasil (2004).
} 
A técnica de coleta de dados adotada neste estudo foi a técnica de Grupo Focal. Esta técnica tem origem anglo-saxônica, e inicialmente era utilizada para pesquisa no campo do marketing, entre a década de 1940 e 1950 do século XX (KIND, 2004; TRAD, 2009). È possível defini-la como uma técnica de pesquisa que coleta dados por meio de interações grupais ao se discutir um tópico especial sugerido pelo moderador/pesquisador, visando reunião um grupo de pessoas com interesses, experiências ou características demográficas similares a fim de colher informações que possam proporcionar a compreensão de percepções, crenças, atitudes sobre um determinado tema (GONDIM, 2002; MOURA \& FERREIRA, 2005; TRAD, 2009). Como técnica, ela ocupa uma posição entre a observação participante e a entrevista em profundidade (GONDIM, 2002).

A presente pesquisa foi realizada com dez mulheres rurais de idades entre 20 e 74 anos. Durante o desenvolvimento do Grupo Focal, observamos que as opiniões das mulheres mais velhas, com idade entre 53 a 74 anos e das mulheres mais jovens, com idade entre 20 a 49 anos se diferenciavam, embora sempre se aproximassem no todo.

Para o desenvolvimento da pesquisa, procurou-se atender ao que é recomendado na literatura especializada (GONDIM, 2002; KIND, 2004; TRAD, 2009), sobre os critérios de aplicação da técnica do Grupo Focal: o reduzido número de participantes, atendo-se à média recomendada de seis a quinze entrevistados; a escolha de um local adequado, que vise ao conforto, à privacidade e à acessibilidade dos participantes, recorrendo-se a espaços comunitários; a duração razoável dos encontros, com média de 90 (noventa) a 110 (cento e dez) minutos, para que, a um só tempo, houvesse tempo hábil para realização da técnica; a delimitação da quantidade de encontros, para que o procedimento não fosse cansativo para os participantes; e por fim, a elaboração de um roteiro prévio, visando à saturação do tema discutido, como indicativo de que a estrutura de significados tenha sido adequadamente apreendida.

Os temas que presidiriam as discussões foram a família, educação dos filhos e lembranças da infância e juventude. A execução da técnica grupal proporcionou a obtenção dos dados empíricos necessários a essa pesquisa.

A coleta de dados foi realizada, então, através da técnica de grupo focal, por meio de 04 (quatro) encontros realizados em um espaço público da comunidade, acordados antecipadamente, com as participantes e a aplicação de um questionário fechado contendo perguntas de caráter socioeconômico. Os encontros, com duração média de 90 (noventa) minutos, ocorreram no período abrangendo o segundo semestre de 2011 e o primeiro semestre de 2012, com data e horário previamente combinado, de acordo com a disponibilidade das participantes. As sessões foram transcritas e contou com a participação da moderadora/pesquisadora e de uma observadora com experiência em trabalho com grupos. Optamos pela construção prévia de um roteiro de perguntas a serem abordados durante os encontros com o grupo, visando orientar os tópicos para discussão.

Durante a aplicação da técnica de grupo focal, notamos que as participantes passaram a relatar com mais facilidade suas opiniões e experiências vividas. É importante destacar que o presente estudo não pretendeu a tomada de amostras representativas e, por conseguinte, não teve como intenção que seus achados viessem a representar uma visão geral acerca do tema proposto. $\mathrm{O}$ convite, bem como a participação, foram de caráter voluntário, e as pessoas que autorizaram o uso dos dados fornecidos, foram devidamente informadas do objetivo da pesquisa, além de receberem um termo de conduta ética, que são distribuídos aos participantes, por se tratar de uma pesquisa realizada com seres humanos, 
com propósitos de informar sobre os objetivos do estudo e os direitos aos participantes, como o de recusa, interrupção da participação e do sigilo das informações prestadas." após serem informadas dos objetivos da presente pesquisa.

Os dados socioeconômicos demonstrado no questionário aplicado as mulheres estudado apontam como principais dificuldades para a permanência na escola, a longa distância de suas residências; ao número insuficiente de escolas na comunidade e a falta de transporte adequado para darem continuidade aos estudos nas escolas situadas na sede do município.

O espaço rural evidenciado pelas mulheres nesse estudo desempenha um papel fundamental na memória social desse grupo. Conforme aponta Halbwachs (2006), os grupos estão naturalmente ligados a um lugar e não há memória sem um referencial espacial.

O ambiente rural é, sem dúvida, lugar de condição e suporte de relação, de espaços de convivência, de particularidades (SANTOS, 1999). Fomenta, marcas na memória, já que esses lugares não são apenas uma demarcação geográfica, mas são construídos social e historicamente, gerando representações sobre esses espaços vividos, denota-os de um sentido ou, melhor, de múltiplos sentidos (MENDES \& ALMEIDA, 2007). Ainda como aponta Serpa (2006, p. 15), "é preciso, sobretudo, pensar o espaço como algo dinâmico e mutável, reflexo e condição da/para a ação dos seres humanos, como espaço vivido e, por isso mesmo, 'representável', algo passível de 'apropriação"”.

Claro que as relações do grupo com o lugar é sempre mutável e dinâmico, e as modificações sofridas no espaço repercutem no grupo, bem como na produção de sua memória social. Cada participante da pesquisa vivenciou de forma comum e diferenciada a relação com o espaço da sua comunidade rural. Há uma diversificada percepção desse espaço pelas pesquisadas conforme seus grupos de idades, que apresentaram suas experiências com relação às mudanças econômicas, estruturais e sociais que localidade do Santo Antônio passou.

A partir dos dados do questionário sócio-demográfico, foi possível identificar dois parâmetros de respostas, semelhantes em certas faixas etárias das participantes da pesquisa. No grupo das mulheres mais velhas, a faixa etária variava entre 74 (setenta e quatro) anos, da mais velha, e 53 (cinquenta e três) anos, composto por 05 (cinco) mulheres. No grupo das participantes da pesquisa mais jovens, composta também por 05 (cinco) mulheres, a faixa etária variava entre 49 (quarenta e nove) anos, da mais velha, e 20 (vinte) anos, da mais jovem. Foram assim associadas, pois dentro do grupo, elas tiveram maior concordância nas respostas relacionadas aos temas propostos nos encontros. As participantes da pesquisa vivenciaram as principais mudanças ocorridas no município e na localidade do Santo Antônio.

O grupo das mulheres mais velhas nasceu e passou a infância no inicio da década de 1940 do século, no mesmo momento que surgia a localidade, e quando a Barra do Choça ainda era distrito rural do município de Vitória da Conquista. A juventude e a fase adulta delas coincidem com o período da emancipação do município e a elevação da zona rural como povoado, na década de 1960, além do surgimento da primeira escola na localidade, em 1963. 
No grupo das mulheres mais novas, o panorama é diferenciado. A maioria destas nasceu e passou a infância em um contexto de conquistas do município e da localidade, já batizada de Santo Antônio, no período da década de 1980 do século XX. Neste momento, já existia uma escola na localidade, fator para se identificar um maior número de mães letradas neste grupo, mas esta instituição aparecia de forma insuficiente naquela época, já que os poucos anos de estudos da maioria das mulheres deste grupo são atribuídos ao difícil acesso à escola. Suas juventudes e fase adulta coincidem com o surgimento de diversos serviços, como a construção de mais escolas e da unidade de saúde, bem como a ampliação da rede pública de saneamento básico e energia elétrica.

Atualmente, a localidade rural do Santo Antônio possui algumas peculiaridades, quando comparadas com outras regiões do município. Esta comunidade rural evidencia, através de números, uma nova realidade ao se caracterizar o meio rural brasileiro, que hoje é extremamente complexo. Ainda encontram-se evidências de uma classificação de que o "urbano" seria o novo, o progresso e o "rural" com o velho, como o atrasado (SILVA, 1997), numa tentativa de se diferenciar esses dois espaços. Entretanto, esta denominação se mostra inadequada, principalmente ao se tomar como exemplo a comunidade estudada nesta pesquisa. Atualmente, está cada vez mais difícil delimitar o que é rural e o que é urbano (MINGIONE \& PUGLIESE, 1967).

Podemos dizer que rural hoje é entendido como um "continuum" do urbano do ponto de vista espacial; e do ponto de vista da organização da atividade econômica, as cidades não podem mais ser identificadas apenas com a atividade industrial, nem o campo com detentores unicamente das atividades agricultura e a pecuária. Em poucas palavras, o meio rural brasileiro se urbanizou nas duas últimas décadas, como resultado do processo de industrialização da agricultura, de um lado, e, de outro, do transbordamento do mundo urbano naquele espaço que tradicionalmente era definido como rural (SILVA, 1997). Notamos que a comunidade do Santo Antônio demonstra esta atual conjuntura, pois possuem acesso a serviços, demonstrado nos números semelhantes ou até superiores quando comparada a outras zonas rurais, à zona urbana e ao município como um todo. Isto evidencia o histórico de lutas, manifestações e conquista desta população para melhoria da comunidade. Para melhor visualização desse panorama, apresentamos na tabela 4.1.1, um levantamento estatístico sobre as condições de saneamento básico, acesso a serviços públicos, condições de moradia e escolarização da comunidade estudada.

A história de formação do município e seu paralelo com a comunidade rural que as participantes da pesquisa residem demonstram como o espaço desempenha um papel importante na memória social, como evidenciado por Halbwachs (2006). Não há, segundo esse autor, memória social que aconteça independente de um contexto espacial, que recebe e imprime marcas nos grupos aos quais se relacionam. E, também, como saliente Halbwachs (2006), a memória social carrega consigo as mudanças na relação do grupo com o espaço, como àquelas ocorridas nas memórias do grupo de rurais em relação às transformações do município de Barra do Choça.

\section{Memória e Gênero em mulheres rurais.}

Essas lembranças evocadas pelo grupo de mulheres mais velhas evidenciam o papel da mulher da década de 1950 e início da década de 1960 pautado pela realização no casamento e maternidade. $\mathrm{O}$ estudo não era a opção mais difundida, principalmente nas classes sociais menos favorecidas, não obstante, a necessidade de geração de renda já era uma realidade para este grupo social (BASSANEZI, 2004). 
Naif (2008) retrata que na sua pesquisa que as mulheres mais velhas e mães, casavam, constituíam família e tinham filhos muito cedo, e lembravam positivamente do casamento. As viúvas, por sua vez, atribuíam o sofrimento ao falecimento precoce dos maridos e a necessidade de criar os filhos de maneira solitária, evidenciando uma realidade entre as famílias de baixa renda como matrifocais, em que possuem em sua composição parentes, filhos e a mulher figurando como central na manutenção da família, em que o homem é uma figura provisória e temporária (NAIFF \& SÁ, 2007), constatado também esta evidência nesse grupo de mulheres entre 53 (cinquenta e três) a 74 (setenta e quatro) anos.

Outros relatos surgiram, mas de forma pouco acentuada, comparando as vivências na infância, consideradas melhores pelo grupo de mulheres mais velhas, já que elas tiveram acesso a um espaço com mais simplicidade, maior respeito aos pais e figuras de autoridade e a uma harmonia familiar, e com seus filhos enfrentam situações de desrespeito, conflitos, mais exigências de coisas materiais, etc.

Notamos,entretanto, no grupo das mulheres mais jovens, que os elementos mais evocados estavam associados ao fato de seus filhos terem tido acesso à escola, dada a expansão do número de escolas, dos meios de transporte na comunidade, o que facilitou que tivessem acesso à educação e frequentassem a escola como uma condição necessária para que pudessem "ter um futuro melhor, sem sofrimento e nem dificuldades" 4 . As participantes referenciavam a educação formal como instrumento e meio legítimo de ascensão social para seus filhos.

As mulheres mais jovens evocavam a importância do acesso de seus filhos à informação e a outras oportunidades, assim como os consideravam mais saudáveis pelo fato de usufruírem mais ações de promoção e prevenção em saúde e outras políticas públicas, confirmando esta tendência a partir do aparecimento de incentivos financeiros para as famílias de baixa renda (SENNA et al., 2007). Entretanto, consideravam que havia elementos negativos na educação dos filhos, como desobediência, falta de respeito, que elas não conseguiam resolver. Buscando uma referência no passado, na relação com seus pais ressaltavam que em seu tempo isso não ocorria. De certo modo é um reflexo daquilo que Sánchez (1995) afirma das mudanças nas relações familiares:

A perda do poder dos pais em relação aos filhos provoca com frequência uma falta de disciplina. A disciplina autoritária dá lugar a uma falta de controle sobre as condutas dos filhos, especialmente dos filhos adolescentes, que pode chegar a impedi-los de exercer de maneira eficaz seu dever de protetor (SÁNCHEZ, 1995, p. 14, tradução livre ${ }^{5}$ ).

A dificuldade de estabelecer um diálogo familiar com seus filhos era muitas vezes justificada nas falas dessas mulheres mais jovens, pelo fato de não saberem lidar com as novas demandas ou necessidades dos filhos. Remetiam-se ao passado para questionar o presente, uma vez que os filhos estavam exigindo muitos dos pais, como na fala de duas participantes:

\footnotetext{
${ }^{4}$ Fala produzida por uma das participantes.

${ }^{5}$ No original em espanhol: "La perdida de poder de los padres em relación com loshijosprovocanfrecuencia uma falta de disciplina. La disciplina autoritaria de paso a uma falta de control sobre laconducta de loshijos adolescentes, que puedellegar a impedirlesejercer de manera eficaz sudeberprotector."
} 
"Meus filhos hoje têm mais oportunidades do que eu tive, tem escola, tem saúde, tem muito mais coisas do que eu tive. Hoje, eles não precisam trabalhar, só estudar". Relato da participante R dos S. M., de 42 anos.

"Meus filhos reclamam quando não tenho dinheiro para dar alguma coisa para eles, mas falo que, na minha infância, eu não podia pedir aos meus pais, tinha que trabalhar. Os filhos de hoje não sabem valorizar o que têm, pois não precisam passar dificuldade". Relato da participante A.A.S., de 30 anos.

Os elementos evocados pelas participantes da pesquisa estavam associados à infância dos filhos, sempre referenciados na própria infância vivida. Confirma-se, assim, a análise de Peralta (2007): a memória fornece referentes de significações constituídos por visões partilhadas do passado, que são geradas pelo presente e orientadas para o futuro eimplica uma constante dialética entre o passado, o presente e o futuro. Ainda segundo a autora:

A memória social é, assim, constituída pela integração de diferentes passados num passado comum aos membros de uma coletividade, referindo-se àqueles elementos da recordação individual que são comumente partilhados pelo grupo, fornecendo as bases para a construção de uma significação coletiva. [...] Em suma: a construção do passado, embora assentando sempre em quadros de significação e em contextos culturais específicos, não deixa também de estar moldada pelas experiências emocionais e pelas expectativas pessoais de cada indivíduo (PERALTA, 2007, p. 19).

Era a partir da percepção da infância dos filhos que as participantes da pesquisa produziam evocações sobre a infância, apoiadas pelas suas próprias rememorações. Como ressalta Bosi (2010), essa memória sobre a infância se aproxima, pela sua força e espontaneidade, da pura evocação.

No núcleo central, as mulheres mais velhas, entre 53 (cinquenta e três) e 74 (setenta e quatro) anos de idade, apresentavam uma evocação maior de elementos e narrativas associados a uma infância pobre, quando exerceram o trabalho muito cedo, porém associavam a um período de vida feliz.. Como pode ser observado no Quadro 6 a seguir:

Notamos que os principais elementos evocados por todas as mulheres mais velhas foram uma infância marcada pelo trabalho e as dificuldades financeiras, mas, para muitas, havia o componente prazeroso e de boas relações na família. O trabalho rural na infância apareceu no relato das lembranças de todas as mulheres, mas, em alguns elementos periféricos, não figurou como algo condenatório por elas, referendando a pesquisa realizada por Nascimento (2004), quando ressalta que, muitas vezes, essas lembranças trazem certo tom nostálgico e saudoso do trabalho na infância. Nessa temática, identificamos os primeiros elementos conflitantes, como podemos destacar pelo relato de uma das participantes:

"Meu pai não me deixava ir para a escola, que era longe da nossa rocinha (ficava na sede do então distrito de Barra do Choça), pois ele dizia que mulher não precisa saber ler e nem escrever, que mulher 
não precisa saber escrever para mandar bilhetes para namorados" (Relato da participante C. dos Santos, 74 anos).

Essas evocações das participantes evidenciavama ausência da escola em suas vidas, associando-a às dificuldades financeiras que viveram e à necessidade de trabalhar durante a infância. Como aponta Noronha (1986), muitas vezes as mulheres no meio rural são privadas da educação escolar para se educarem através do trabalho, como mostra esses relatos:

"Só não pude estudar, porque, desde os dez anos, trabalhava eu e meus irmãos como vaqueiros do meu pai na roça dos outros". A. P. S., de 70 anos.

Cordeiro (2012) evidenciou, em sua pesquisa com mulheres trabalhadoras rurais do sertão pernambucano, que são atribuídos às mulheres na área rural espaços socialmente circunscritos: a casa, o grupo familiar e a comunidade a que pertencem; cabendo aos homens lidar com outros espaços sociais: gestão da unidade familiar, aquisição de equipamentos para o trabalho, comercialização dos produtos e comércio de terras, liberdade para sair, beber com os amigos, ir às festas e jogos, não necessariamente acompanhados da família.

Nos relatos das participantes mais velhas não foram claramente evidenciados esses conflitos e essas novas formas de organização da produção familiar, o que não significa que relações de autoridade, poder e gênero na conjuntura familiar não existissem na realidade delas.

É interessante observar que mesmo a relação da infância agradável estava permeada pelo trabalho infantil, pelo analfabetismo e pela falta da escola. É importante destacar que o não acesso à escola deve também ser compreendido no contexto sócio-histórico da região já apresentada, já que a primeira escola a ser instalada, ainda quando era distrito de Vitória da Conquista, foi no ano de 1953, período em que boa parte das participantes já tinha idade escolar, mas não tinha condições financeiras para se descolar até a sede do distrito, indicativo da histórica fragilidade da educação escolar no meio rural. Neves (2007) também identifica, em seu trabalho sobre as representações sociais da escola de mulheres e homens de um assentamento, essa dificuldade de acesso à escola no meio rural. Contudo, as participantes não apresentaram, como explicação para os problemas, a falta da instituição escolar no povoado em que habitavam, mas a dificuldade de deslocamento para a escola, que se localizava na sede do distrito.

Naiff\& Sá (2007) e Naiffet al. (2008), em pesquisa sobre representação da educação escolar e memórias autobiográficas de mães e filhas de baixa renda, habitantes de uma periferia do Rio de Janeiro, constataram que o trabalho na infância marcou bastante a trajetória de vida das mulheres do grupo das mães. Elas associaram poucas lembranças boas a essa fase, em que as dificuldades financeiras foram marcantes, emergindo dessas memórias a preocupação em poupar as filhas do trabalho infantil para diferir de sua própria realidade. As pesquisas de Azevedo (2011) também evidenciam que memórias recompostas de exclusão escolar por parte de mães trabalhadoras rurais foram elementos decisivos na inserção desvantajosa no contexto de distribuição social do acesso à educação, através da entrada precoce do trabalho em suas vidas, que se apropriou da infância, tornando-as adultas precocemente na medida em que incorporaram em seu cotidiano a 
assunção das tarefas de manutenção da família. Em tal contexto, o tempo da escola se tornava secundário diante do tempo do trabalho.

Nenhuma das participantes mais velhas evocou o exercício do trabalho remunerado na infância; elas apontavam em seus relatos a execução de dois tipos principais de trabalhos, os quais as privavam do acesso ou permanência na escola: o trabalho doméstico e o trabalho na propriedade rural da família. Como ressalta Noronha (1986), o trabalho infantil exercido na roça era relatado pelas mulheres como uma "ajuda" à família, pois trabalhavam na própria propriedade ou auxiliavam seus pais no serviço.

Já no grupo das mulheres mais jovens, havia uma relação mais nostálgica e valorativa quando elas narravam as recordações da infância. Relembravam com riqueza de detalhes os principais jogos de criança, o acesso maior ao espaço público e às "brincadeiras de rua", uma experimentação maior do lazer nos tempos de criança e atribuíam a uma escolha pessoal, na maioria dos casos, e não a uma imposição familiar ou circunstancial, a busca pelo trabalho na lavoura, principalmente na adolescência:

"Tive uma infância feliz. Ia para a escola pela manhã e ajudava minha mãe na roça e em casa pela tarde. Só que não pude terminar os estudos". Relato da participante P. S. dos S., de 30 anos.

"Tive uma infância muito boa, brincava na rua de pega-pega, bandeirinha, corria, nadava no rio e estudava também."Relato da participante A. dos S., de 30 anos.

Identificamos que os relatos do grupo estava associadas à importância da escola e à dificuldade de conseguirem permanecer na escola e concluir os estudos. A necessidade de trabalhar na adolescência era apontada como principal motivo do abandono escolar. Nos elementos periféricos, também eram reforçadas e evocadas as dificuldades de acesso à escola e permanência na instituição escolar, já que, no período da infância e juventude vividas pelas participantes, existia somente uma única escola para atender a toda a comunidade e, para dar prosseguimento aos estudos, era necessário ir à sede do município para estudar. Nesse grupo, entretanto, a pouca permanência escolar era muito mais relacionada às dificuldades financeiras vividas pela família; atribuíam a esse motivo a não continuidade dos estudos.

Entretanto, não foi apenas no grupo das mulheres mais velhas que ocorreu o contraste entre uma infância boa e uma infância marcada pelo trabalho, que as impedia de ir à escola. Essa característica figurou também nas memórias das mulheres mais jovens, conforme depoimento de uma das participantes, que nos contou sua trajetória de trabalho infantil e as dificuldades para ajudar a mãe no sustento da família:

"Minha infância não foi muito boa não, pois tive que trocar o lápis pela enxada. Larguei a escola porque era a irmã mais velha e tive que ajudar para pôr comida em casa para sustentar meus irmãos, depois que meu pai sofreu um acidente. Eu tinha dez anos." Relato da participante A. A. S., de 30 anos.

Podemos fazer um paralelo com outros estudos em que as mulheres de uma geração mais recente falam desse maior tempo de lazer, resgatam boas lembranças da escola e revelam a mudança para um mundo adulto em consequência da escolha em para se dedicarem ao mundo do trabalho e às vivências sexuais (NAIFF \& SÁ, 2007). Diferente 
dos relatos das mulheres mais velhas, em que o matrimônio não figurou como elemento representativo da infância, certamente pelo fato de terem se casado já na maioridade, após os 18 (dezoito) anos. Para Magalhães (2010), embora as novas gerações tenham alcançado diferentes oportunidades de escolarização e diversificação nos setores ocupacionais, quando comparadas às mães e avós, ainda sofrem de uma relação desigual de gênero:

[...] A cada dia é possível deduzir, diante dos dados da realidade, que continuam testemunhando e convivendo com 'tipos sociais de mulheres', que aparecem cada vez mais vinculados a uma rede imbricada de condições sociais, coletivas, familiares e culturais, que são superpostas ao seu desempenho social. Uma realidade onde as questões de gênero, de certa forma, aparentemente, aparecem resolvidas ou atenuadas, quando se observa o crescimento de sua inserção no trabalho,na composição da renda familiar, na educação. Contudo, os próprios dados indicam que anda persistem as desigualdades de gênero, embora não se possa deixar de ressaltar, por sua vez, que as mulheres aparecem e ganham visibilidade em vários espaços sociais, tornando evidentes essas contradições e, quiçá, apresentando outros enfrentamentos e perspectivas com vistas a sua superação (MAGALHÃES, 2010, p. 87).

A memória comum das mulheres pesquisadas parte do contexto rural de dificuldades que as impedia de ter acesso à escola e de uma diferenciação de gênero, uma vez que referenciam à condição social de mulher no espaço doméstico e privado. Para Jedlowski (2001), a dimensão social da memória social também é evidenciada pelas narrativas e expressões associadas a um contexto.

Em resposta ao questionário socioeconômico, as mulheres mais velhas confirmaram que, no seu tempo, entre os anos 40 e 50 do século XX, não tinham direito ao acesso à escola, já que todas nunca freqüentaram a sala de aula. Já as mulheres mais jovens freqüentaram a escola, entretanto os poucos anos de escolarização evidenciam a dificuldade de permanecerem na escola. Noronha (1986), em sua pesquisa com trabalhadoras rurais, elenca algumas razões que mantêm essas crianças afastadas da escola no meio rural:

[...] a subordinação de seu tempo e de seu ritmo ao ciclo agrícola, a necessidade de abandonar os estudos antes do tempo regular, o estado de precariedade das escolas que costumam freqüentar, a distância geográfica entre as escolas e sua casa, o desinteresse pela escola, a reprodução do ciclo de esvaziamento dos conteúdos nos professores mal preparados, a repetição seguidas vezes da mesma série, a dificuldade de os pais acompanharem as atividades escolares, a falta de tempo e de condições pedagógicas (NORONHA, 1986, p. 210).

As participantes da pesquisa de ambos os grupos afirmaram ter experimentado impedimentos, durante a infância, para freqüentar a escola, cada uma em sua época: algumas não tiveram direito algum de freqüentara escola, outras não puderam dar prosseguimento aos estudos.

As mulheres mais maduras participantes do estudo traziammarcas mais profundas em seus relatos, como a miséria e a dificuldade financeira enfrentada pela família, temática que apresentava evocações, para algumas, elementos distintivos que indicavam uma vivência particular do trabalho realizado na infância, mesmo com a falta de leis que protegessem a criança trabalhadora, significou um momento de estar próximas dos pais, 
sendo algo positivo, como destacamos no relato de uma das participantes. Para todas as participantes do grupo das mulheres mais velhas, o matrimônio na fase de transição entre a infância e a adolescência (entre 11 e 14 anos) antecipou a vida adulta. Como atesta Jelin (2002, p. 99): "os símbolos de dor e de sofrimento personalizados tendem a se incorporar mais nas mulheres".

"Não pude estudar, sabe? Porque desde dos dez anos trabalhava eu e meus irmãos como vaqueiros do meu pai na roça dos outros. Era bom, ficava a família toda junta e a gente aprendia a mexer com bicho, a mexer na roça". A.P.S., de 70 anos.

A relação entre infância, miséria e pobreza, que figurou tanto nos elementos centrais como nos periféricos das mulheres mais velhas, traziam à tona circunstâncias que as mantiveram afastadas do acesso à escola. Essa instituição parece representar um papel fundamental para esse grupo, que se contrasta com a realidade de suas vidas e de seu passado. Nessas mulheres, as suas memórias são marcadas pela negação do acesso à escola. Em seus relatos, a escola figurava como elemento bastante expressivo dos relatos, por significar um ideal de vida melhor não alcançado e por ser um espaço idealizado e idílico, que resolveria boa parte dos problemas atuais.

A situação das mulheres do grupo retrata a mulher da década de 1950 e início da década de 1960, ainda bastante pautada pela realização no casamento e na maternidade. Percebemos que esse fato não ficou evidenciado no grupo das mulheres mais jovens, que não trouxeram como recordação relatos relacionados à privação do espaço público.

Todas as mulheres do grupo das mais velhas relataram que seus filhos frequentaram a escola, e todas do grupo das mais jovens relataram que seus filhos atualmente frequentam a escola, demonstrando a importância da educação para as participantes da pesquisa. Essa relevância atribuída à escola também foi identificada por Noronha (1986), em sua pesquisa sobre o trabalho feminino e relações de saber no meio rural, em que a escola aparecia como importante para a formação das trabalhadoras e principalmente dos filhos, pois consideravam que ir à escola era condição para que seus filhos se tornassem pessoas que compreenderiam melhor o mundo.

As mulheres mais jovens que tiveram acesso à escola relataram recordações considerando sempre as experiências vividas no espaço institucional escolar, evidenciando marcas de suas representações sobre a escola. A memória representacional de uma escola que fazendo referência ao cotidiano escolar, como a ambiência no espaço físico, os colegas de sala de aula, os comportamentos produzidos no momento da aprendizagem, as relações com os docentes e a instituição como um lugar acolhedor. Para Halbwachs (2006), as imagens espaciais desempenham um papel de marca importante na memória social, o que observamos no relato de nossas participantes, já que elas frequentaram a mesma escola da comunidade e tiveram os mesmos professores. Ainda segundo o sociólogo:

[...] Quando inserido numa parte do espaço, um grupo o molda à sua imagem, mas ao mesmo tempo dobra e se adapta a coisas materiais que a ela resistem. $\mathrm{O}$ grupo se fecha no contexto que construiu. A imagem do meio exterior e das relações estáveis que mantém com este passa a primeiro plano da ideia que tem de si mesmo (HALBWACHS, 2006, p. 159). 
Notamos que, nos relatos das mulheres, as vivências do cotidiano escolar estavam fortemente marcadas na memória social do grupo. Exemplo disso é a presença da lembrança de docentes que marcaram a fase escolar de muitas participantes desse grupo etário:

"Lembro até hoje de meus professores, e tinha uns dois que eram bem exigentes. Eram bons professores, só não gostavam que a gente bagunçasse na sala. Muitas pessoas lembram desses professores aqui da comunidade." Relato da participante A. dos S., de 30 anos.

Outro dado relevante que destacamos é a presença da dificuldade de acesso à escola também nesse grupo de mulheres, que as diferenciava das mais maduras, já que as mulheres mais jovens tiveram, ainda que de forma limitada, acesso ao ensino básico, mas as dificuldades se encontravam na falta de condições financeiras de prosseguir nos estudos nas escolas situadas na sede do município, que oferecia as demais séries do ensino fundamental e do ensino médio:

"Comecei a estudar tarde, com 7 anos de idade, porque não tinha escola para crianças menores na comunidade. Gostava muito da escola, mas tive que abandonar os estudos aos 11 anos, pois não tinha condições de estudar na sede no município, já que só tinha vaga para uma pessoa no carro que levava para a cidade e para meu pai não ter que escolher entre eu e meu irmão, os dois ficaram sem estudar. Lembro até que, por gostar tanto da escola, eu repeti a $4^{\text {a }}$ série para não deixar de estudar e ter que sair da escola", Relato da participante R. dos S. M., de 42 anos.

Podemos notar que as manifestações de ambos os grupos sobre a escola foi de positivá-la, trazendo-a como algo importante. Para as mulheres que não tiveram acesso, a escola figurava como o espaço que lhes daria melhores oportunidades. Para as participantes que não puderam dar continuidade aos estudos, a escola era relacionada a um momento da vida de boas recordações. Mas, como afirma Halbwachs (2006), a lembrança é mais do que memória, é também representação. Não houve destaque, pelas participantes do grupo das mulheres mais velhas, da negação do acesso à escola, e, pelo grupo das mulheres mais novas, da precarização que a escola pública apresentava naquele momento. Para o mesmo autor, em outra obra, tendemos a selecionar rememorações mais positivas e escamotear aquelas menos agradáveis (HALBWACHS, 2004).

A memória comum apresentada pelo núcleo central de todas as mulheres em estudo acerca da escola, em que ficou evidente que não tiveram acesso ou tiveram acesso restrito, se referenciava a um quadro social (HALBWACHS, 2004) demarcado por um contexto rural de dificuldades econômicas e sem condições de acesso a bens sociais, como a escola. Mas também a um quadro social baseado em valores diferenciados de gênero, pela condição social da mulher no espaço doméstico e privado, familiar e de trabalho, localizado no espaço rural.

\section{CONCLUSÕES}

Observamos que os quadros das memórias dos dois grupos de mulheres estudadas são referenciados no espaço rural e na família. Elas evocavam os lugares, a depender de suas idades, as memórias comuns e distintas, de acordo com o tempo vivido. Notamos que se desenhava uma tendência das participantes da pesquisa em relatar acontecimentos de 
suas infâncias, o local em que viviam, o que havia mudado, o que havia de diferente do hoje para o ontem. Os conteúdos mais evocados por suas lembranças eram relacionados à infância e à situação de privação. As atividades junto aos pais e à família, que poderiam ser caracterizadas como trabalho, eram corriqueiras nos seus relatos e havia certo tom nostálgico em suas narrativas.

As memórias evocadas por cada grupo eram permeadas por um aspecto central: a importância da escola e da educação. Para as participantes da pesquisa, a educação escolar se configurava como aquela responsável pela melhoria de vida dos filhos, como o caminho que daria acesso a novas oportunidades, o lugar de ascensão social, de sair da pobreza e de não exercer um trabalho pesado quando crianças. Entretanto, em contraste com essa visão positivada da escola, as mulheres ressaltaram as dificuldades que tinham com a educação não formal de seus filhos, aquela que elas tentam fornecer aos filhos em contraste com a educação familiar que elas tiveram.

Contudo, a referência à escola quase sempre aparecia como um "direito" negado ou de difícil acesso e como uma conquista que queriam garantir a seus filhos. A escola surgia como o espaço construído especialmente para fornecer instrução e conhecimento às crianças e para lhes apresentar as regras de socialização, servindo como uma ponte entre o cotidiano privado das famílias e o espaço externo e social (VASEN, 2008). No atual cenário, "a escola tem sido gradualmente a responsabilidade inevitável para intervir na produção social de sentidos sobre o passado recente" (FALCHINI, 2008, p. 01).

Os dados que apresentamos indicam que, nos relatos do passado e das vivências, há uma necessidade de mostrar o presente, particularmente a educação dos filhos, trazendo aspectos culturais, socioeconômicos, influências sociais, crenças e percepções que estruturaram o passado trazido à tona pelo seu porta-voz, o sujeito que lembra (NAIFFMIGUEZ \& SÁ, 2007). Essas lembranças da infância, segundo Halbwachs (2004), só seriam conservadas em razão da memória social. Ainda sobre as rememorações da infância, reafirmando Carli (2011), a memória da infância se fabrica através da escritura adulta, produzindo-se uma particular apropriação do passado.

Confirmamos, com os relatos coletados, a importância da escola. Como apontam Naiffet al. (2008), esta escola positivada é muitas vezes idealizada nas lembranças e representações, contrapondo com a realidade em que esse espaço social se mostra pouco sensível às questões trazidas pelas camadas mais pobres da população. Assim como a escola, a família também sofre influência do contexto histórico e cultural. E as mudanças ocorridas historicamente na definição e na organização da família são percebidas pelos dois grupos de mulheres rurais. Notamos que as participantes mais velhas ainda sofreram as determinações das famílias patriarcais e tradicionais, enquanto as participantes mais jovens já acompanharam algumas mudanças dentro de suas famílias.

Ressaltamos que nossa pesquisa confirma a manutenção, nesse espaço rural, das relações desiguais de gênero. As mulheres rurais continuam exercendo múltiplas funções: dona de casa, esposa, mãe, trabalhadora rural, safrista, proprietária e lavradora de sua própria terra (NORONHA, 1986), mesmo com a conquista, enquanto ideia na sociedade, de igualdade entre homens e mulheres, como reitera Jelin (1995). Frisamos que as relações de gênero necessitam vir à tona, a fim de superar a realidade que ainda esconde situações de exploração e de desigualdade de gênero e que reflete na formação e transmissão das gerações, incidindo nas relações e no cotidiano da vida pública e privada, como analisa Magalhães (2010). 


\section{REFERÊNCIAS}

ABRIC, Jean Claude. A abordagem estrutural das representações sociais. In A. S. P. Moreira \& D. C. de Oliveira. (Orgs.). Estudos interdisciplinares de representação social. (pp. 27-38). Goiânia: AB, 1998.

ALBA, Martha de. Representações sociais e memória coletiva; uma releitura. In. Teoria das representações sociais: 50 anos. Angela Maria de Oliveira Almeida; Maria de Fátima de Souza Santos; Zeidi Araújo Trindade (org). Brasília: Technopolitik, 2011, pp. 393-432.

ALVES, Ana Elizabeth Santos; CUNHA, Tânia Rocha Andrade. LIVRO DE COSTURA SINGER: Fonte documental para os estudos sobre trabalho e gênero. Revista HISTEDBR On-line, $\quad$ v. $\quad 1, \quad$ p. $1-12, \quad 2009 . \quad$ Disponível em: http://www.fae.unicamp.br/revista/index.php/histedbr/article/view/4070/3373. Acesso em 18 de novembro de 2012.

ARIÈS, Philippe. História social da criança e da família. 2. ed. Rio de Janeiro: LTC, 1981.

ARRUDA, Angela. Teoria das representações sociais e teorias de gênero. Cad. Pesqui., São Paulo, n. 117, nov. 2002 . Disponível em $<$ http://www.scielo.br/scielo.php?script=sci_arttext\&pid=S0100-

$15742002000300007 \& \operatorname{lng}=$ pt\&nrm=iso $>$.

acessos

em 18 nov. 2012. http://dx.doi.org/10.1590/S0100-15742002000300007.

AZEVEDO, Alessandro Augusto. "Trabalhar com os braços e a cabeça para ver o futuro...": Representações sobre educação a partir de trabalhadores rurais assentados da reforma agrária. Educar em Revista, América do Norte, 40, set. 2011. Disponível em: http://ojs.c3sl.ufpr.br/ojs-2.2.4/index.php/educar/article/view/19333. Acesso em: 18 Nov. 2012.

BANCHS, María Auxiliadora. RepresentacionesSociales em proceso: suanálisis a través de grupos focales. In MOREIRA, Antônia Silva Paredes (Org.); CAMARGO, Brígido Vizeu (Org.); JESUÍNO, Jorge Correia (Org.); NÓBREGA, Sheva Maia (Org.). Perspectivas teórico-metodológicas em representações sociais. $1^{\text {a }}$ ed. João Pessoa: Editora universitária da UFPB, 2005, v. 1, pp. 401-424.

BARDIN, Laurence. Análise de conteúdo. Lisboa: Edições 70, 2007.

BARROS, Manoel de. Memórias Inventadas: A Infância. Rio de Janeiro: Planeta, 2009.

BASSANEZI, Carla. Mulheres dos anos dourados. In Del Priore, Mary (Org.), História das mulheres no Brasil.São Paulo: Contexto, 1997, pp. 607-639.

BRASIL. Diretrizes do NASF- Núcleo de apoio à saúde da família. Ministério da Saúde. Secretaria de Atenção à Saúde. Departamento de Atenção Básica. Brasília : 2009, (Série B. Textos Básicos de Saúde) (Cadernos de Atenção Básica ; n. 27)

BREDA, Bruna. Infância: imagens e memórias de adultos. São Paulo/SP, 2010. Dissertação (Mestrado em Educação. Faculdade de Educação da Universidade de São Paulo. 
BONAN, Claudia. Reflexividade, sexualidade e reprodução. Processos políticos no Brasil e no Chile. Tese de Doutorado. Rio de Janeiro. Instituto de Filosofia e Ciências Sociais/UFRJ, 2002.

BOSI, Ecléa. A pesquisa em memória social. Psicol. USP, São Paulo, v. 4,n. 1-2, 1993.

Memória e sociedade: lembranças de velhos. São Paulo: Companhia das Letras. 16 ${ }^{\mathrm{a}} \mathrm{Ed}, 2010$.

CAMARGO, Brígido Vizeu. Introdução: Estratégias de pesquisa pluri-metodológicas. In MOREIRA, Antônia Silva Paredes (Org.); CAMARGO, Brígido Vizeu (Org.); JESUÍNO, Jorge Correia (Org.); NÓBREGA, Sheva Maia (Org.). Perspectivas teóricometodológicas em representações sociais. $1^{a}$ ed. João Pessoa: Editora universitária da UFPB, 2005, v. 1, pp. 19-24.

CARLI, Sandra. La memoria de lainfancia: estudios sobre historia, cultura y sociedad. $1^{\circ}$ ed. Buenos Aires: Paidós, 2011.

CARVALHO, Maria Eulina Pessoa de. Modos de educação, gênero e relações escolafamília. Cad. Pesqui., São Paulo, v. 34, n. 121, abr. 2004 . Disponível em $<$ http://www.scielo.br/scielo.php?script=sci_arttext\&pid=S0100-

$15742004000100003 \& \operatorname{lng}=$ pt\&nrm=iso $>$.

acessos em 05 nov. 2012. http://dx.doi.org/10.1590/S0100-15742004000100003.

CASAS, Ferrán. Infância: perspectivas psicosociales. Barcelona: Paidós,1998.

CHAVES, Antonio Marcos. O fenômeno psicológico como objeto de estudo transdisciplinar. Psicol. Reflex. Crit., Porto Alegre, v. 13, n. 1, 2000 . Disponível em $<$ http://www.scielo.br/scielo.php?script=sci_arttext\&pid=S0102-

$79722000000100016 \& \operatorname{lng}=$ pt\&nrm=iso $>$.

acessos

em 10 nov. 2012. http://dx.doi.org/10.1590/S0102-79722000000100016.

CORDEIRO, Rosineide de L. M. Gênero em contextos rurais: a liberdade de ir e vir e o controle da sexualidade das mulheres no sertão de Pernambuco. In. Jacó-Vilela, Ana Maria; Sato, Leny (org). Diálogos em Psicologia Social. RJ: Centro Edelstein de Pesquisas Sociais, 2012, pp.133-143.

COUTINHO, Sabrine Mantuan dos Santos; MENANDRO, Paulo Rogério Meira. Relações conjugais e familiares na perspectiva de mulheres de duas gerações: "Que seja terno enquanto dure". Psicol. clin., Rio de Janeiro, v. 22, n. 2, 2010 .

CRUZ, Enêde Andrade da. Técnica de análise estrutural das Representações Sociais. In: Anais do I Simpósio Estadual de Representações Sociais: Educação, Representação Social e Subjetividade. Salvador - Bahia: UNEB, 2007.

DATASUS - Departamento de Informática do SUS. Sistema de informação da atenção básica (SIAB) 2011. Brasília: DATASUS.

FALCHINI, Adriana. La escuela como unactor social enlaconstrucción de la memoria colectivadelpasadoreciente. Anais do IV Congreso Nacional sobre Problemáticas SocialesContemporáneas, Facultad de Humanidades y Ciencias - Universidad Nacional del Litoral, Santa Fe, Argentina, 22 al 24 de octubre de 2008. Disponível em: 
http://www.narrativas-memoria.com.ar/, agosto de 2010. Acesso em 28 de setembro de 2011.

FENTRESS, James \& WICKHAM, Chris. Social Memory. Londres: Blackweel Publishers, 1992, (New Perspectives on the Past).

GONDIM, Sônia Maria Guedes. Grupos focais como técnica de investigação qualitativa: desafios metodológicos. Paidéia (Ribeirão Preto), Ribeirão Preto, v. 12, n. 24, 2002. Disponível em <http://www.scielo.br/scielo.php?script=sci_arttext\&pid=S0103$863 X 2002000300004 \& \operatorname{lng}=$ pt\&nrm=iso $>$. acessos em 18 nov. 2012. http://dx.doi.org/10.1590/S0103-863X2002000300004.

HALBWACHS, Maurice. Los marcos sociales de la memoria. Rubí; Concepción; Caracas: Anthropos; Universidad de Concepción; Universidad Central de Venezuela, 2004.

Centauro, 2006.

A memória coletiva. Tradução Beatriz Sidou. Rio de Janeiro:

IBGE - Instituto Brasileiro de Geografia e Estatística. Censo demográfico 2010. Brasília: IBGE.

JEDLOWSKI, Paolo. Memory and Sociology: Themes and issues. Time \&Society, 10 (1), 29-44, 2001.

JELIN, Elizabeth. Los trabajos de la memória. Madrid: Siglo XXI de España Editores, 2002.

.Familia y género: notas para el debate. inWainerman, Catalina (ed). VivirenFamilia. Buenos Aires. Unicef/Losada, 1995.

JODELET, Denise. Ponto de vista: sobre o movimento das representações sociais na comunidade científica. Temas em Psicologia, Ribeirão Preto, v. 19, n. 1, jun. 2011.

KIND, Luciana. Notas para o trabalho com a técnica de grupos focais. Psicologia em Revista (Impressa), Belo Horizonte, v. 10, n. 15, p. 124-136, 2004.

MAGALHÃES, Lívia Diana Rocha. Educação, história e memória: uma aproximação do estudo geracional. Revista HISTEDBR On-line, Campinas, n.28, p.99 -105, dez. 2007.

.Gênero, participacíon laboral, educacional y procesos formativos. In.

Investigacionesactuales de lasmujeres y del gênero. Santiago de Compostela: Universidad, Servizo de Publicacións. Org. Rita $\mathrm{M}^{\mathrm{a}}$ RadlPhilipp( e intercambio científico), 2010, pp. 81-89.

MARKOVÁ, Ivana. Dialogicidade e representações sociais: as dinâmicas da mente. Petrópolis, RJ: Vozes, 2006.

MENDES, Geísa Flores; ALMEIDA, Maria Geralda. Território e lugar nas representações do Sertão da Ressaca, Bahia, Brasil. Cuadernos de geografîa, v. 16, p. 39-47, 2007. Disponível em: redalyc.uaemex.mx. Acesso em 18 de novembro de 2012.

MINGIONE, Enzo; PUGLIESE, Enrico. A difícil delimitação do "urbano" e do "rural": alguns exemplos e implicações teóricas. Revista Crítica de Ciências Sociais, $\mathrm{n}^{\circ}$ 22, abril 
1967, pp. 83-99. Disponível em: geografia.fflch.usp.br. Acesso em 18 de novembro de 2012.

MOURA, Maria Lúcia Seidl de; FERREIRA, Maria Cristina. Definição da Metodologia. InProjeto de pesquisa: elaboração, redação e apresentação. Rio de Janeiro: EDUERJ, 2005, pp. 49-88.

MOSCOVICI, Serge. A representação social da psicanálise. Rio de Janeiro: Zahar, 1978, (Psyche).

NAIFF, Luciene Alves Miguez; SÁ, Celso Pereira de. De mãe para filhas, o legado da exclusão social: um estudo de memórias autobiográficas. Memorandum, 13, 2007, pp. 8899. Disponível em: http://www.fafich.ufmg.br/memorandum/. Acesso em 18 de novembro de 2012.

NAIFF, Luciene Alves Miguez; SA, Celso Pereira de; NAIFF, Denis Giovanni Monteiro. Preciso estudar para ser alguém: memória e representações sociais da educação escolar. Paidéia (Ribeirão Preto), Ribeirão Preto, v. 18, n. 39, 2008 . Disponível em <http://www.scielo.br/scielo.php?script=sci_arttext\&pid=S0103-

863X2008000100012\&lng=pt\&nrm=iso>.

acessos

em 18 nov. 2012. http://dx.doi.org/10.1590/S0103-863X2008000100012.

NASCIMENTO, Adriano Roberto Afonso do; MENANDRO, Paulo Rogério Meira. UNIVERSIDADE FEDERAL DO ESPÍRITO SANTO Centro de Ciências Humanas e Naturais. Memória dos verdes anos: saudade da infância na música popular brasileira - uma investigação e uma proposta de análise de dados. 2004. xv, 164 f. Tese (Doutorado) - Universidade Federal do Espírito Santo, Centro de Ciências Humanas e Naturais.

NASCIMENTO, Neusa Maria Góes Marques; Freitas, Joseania Miranda; Universidade Federal da Bahia. Faculdade de Educação. Adolescência com prazo de validade: um estudo do impacto da prática educativa em Instituições de Abrigo de Salvador. 2005. 151 f. + Dissertação (Mestrado) - Universidade Federal da Bahia, Faculdade de Educação.

NASCIMENTO-SCHULZE, Clélia Maria, CAMARGO, Brigido Vizeu. Psicologia Social, Representações Sociais e Métodos. Temas em Psicologia da SBP. Ribeirão Preto: v.8, n.3, p.287-299, 2000. Disponível em: http://www.sbponline.org.br/revista2/vol_anteriores/vol8n3.htm. Acesso em 18 de novembro de 2012.

NEVES, Joana d'Arc de Vasconcelos. Projeto vividos representações construídas: as Representações Sociais que mulheres e homens do assentamento CIDAPAR possuem sobre os saberes que buscam na escola para os seus projetos de vida. 2007, 262f. Dissertação (Mestrado). Universidade Federal do Pará, Programa de Pós Graduação em Educação.

NORONHA, Olinda Maria. De camponesa a "madame": o trabalho feminino e relações de saber no meio rural. Edições Loyola, São Paulo, 1986. (Coleção Educação Popular nº 04).

OLIVEIRA, Denize Cristina de; MARQUES, Sérgio Correia; GOMES, Antônio Marcos Tosoli; TEIXEIRA, Maria Cristina Trigueiro V. Análise das evocações livres: uma técnica 
de análise estrutural das representações sociais. In MOREIRA, Antônia Silva Paredes (Org.); CAMARGO, Brígido Vizeu (Org.); JESUÍNO, Jorge Correia (Org.); NÓBREGA, Sheva Maia (Org.). Perspectivasteórico-metodológicas em representações sociais. $1^{\mathrm{a}} \mathrm{ed}$. João Pessoa: Editora universitária da UFPB, 2005, v. 1, pp. 573-603.

PAREDES, Eugênia Coelho. Entrevista: anotações para pesquisadores iniciantes. In MENIN, Maria Suzana de Stefano; SCHIMIZU, Alessandra de Morais. Experiência e representação social:questões teóricas e metodológicas. São Paulo, SP: Casa do Psicólogo, 2005, pp. 131-156.

PERALTA, Elsa. Abordagens Teóricas ao Estudo da Memória Social: Uma Resenha Crítica. Arquivos da Memória: Antropologia, Escala e Memória, 2, 2007. Disponível em: dialnet.unirioja.es. Acesso em 18 de novembro de 2012.

PERROT, Michele. Práticas da Memória Feminina: A Mulher e o espaço público. Revista Brasileira de História 18, ANPUH/Marco Zero, 1989. Disponível em: http://www.anpuh.org/revistabrasileira/public/. Acesso em 18 de novembro de 2012.

PHILIPP, Rita Maria Radl. A modo de introducción: aspectos epistemológicos de lãs investigaciones de lãs mujeres y del gênero. In Investigacionesactuales de lasmujeres y del gênero. Santiago de Compostela: Universidad, Servizo de Publicacións. Org. Rita $\mathbf{M}^{\mathbf{a}}$ RadlPhilipp( e intercambio científico), 2010, pp. 9-21.

ROUSSIAU,Nicolas; RENARD, Elise. Des représentationssociales à l'institutionalisation de lamémoiresociale. Connexion, Paris, n. 80, 2003, p.31-41. Disponível em: http://www.cairn.info/revue-connexions-2003-2.htm. Acesso em 18 de novembro de 2012.

SÁ, Celso Pereira de. Núcleo Central das Representações Sociais. Petrópolis, RJ: Vozes, 1996.

As memórias da memória social. In SÁ, Celso Pereira (org). Memória, imaginário e representações sociais. Rio de Janeiro, RJ: Editora do Museu da República, 2005, pp. 63-86.

Sobre o campo de estudo da memória social: uma perspectiva psicossocial. Psicol. Reflex. Crit., Porto Alegre, v. 20, n. 2, 2007 . Disponível em <http://www.scielo.br/scielo.php?script=sci_arttext\&pid=S0102-

$79722007000200015 \& \operatorname{lng}=$ pt\&nrm=iso $>$.

acessos em 18 nov. 2012. http://dx.doi.org/10.1590/S0102-79722007000200015.

As representações sociais na história recente e na atualidade da Psicologia Social. In: Ana Maria Jacó-Vilela; Arthur Arruda Leal Ferreira; Francisco Teixeira Portugal. (Org.). História da Psicologia: rumos e percursos.2 ed. Rio de Janeiro: Nau Editora, v. 1, p. 587-602, 2007b.

SÁNCHEZ,Félix López. Necessidades de la infância: respuestas familiares. In Infancia y Sociedade: Revista de Estudios, 1995, v. 30, pp. 8-47.

SANTOS, Milton. Modo de produção técnico-científico e diferenciação espacial. Território, IV (6):21-28, jan/jun.1999.

SANTOS, Myrian Sepúlveda dos. Memória coletiva \& teoria social. Rio de Janeiro: Annablume, 2003. 
SANTOS, Álvaro Miranda. Os primórdios de uma disciplina - curso e percuso. In Psicologia Social. Coordenado por Jorge Vala e Maria Benedicta Monteiro. $6{ }^{\text {a }}$ ed. Lisboa: Fundação CalousteGulbenkian, 2004, pp. 13-60.

SCOTT, Joan. Gênero: uma categoria útil para a análise histórica. Recife: SOS Corpo, 1996. Disponível em: http://www.soscorpo.org.br/. Acesso em 18 de novembro de 2012.

SENNA, Mônica de Castro Maia et al . Programa bolsa família: nova institucionalidade no campo da política social brasileira?. Rev. katálysis, Florianópolis, v. 10, n. 1, jun. 2007 . Disponível em <http://www.scielo.br/scielo.php?script=sci_arttext\&pid=S141449802007000100010\&lng=pt\&nrm=iso >.

acessos em 18 nov. 2012. http://dx.doi.org/10.1590/S1414-49802007000100010.

SERPA, AngeloSzanieckiPerret. O Trabalho de Campo em Geografia: Uma Abordagem Teórico-Metodológica. Boletim Paulista de Geografia, v. 84, p. 7-24, 2006. Disponível em: http://agbsaopaulo.org.br/node/156, Acesso em 18 de novembro de 2012.

SILVA, José Graziano da. O novo rural brasileiro. Nova economia, Belo horizonte. 7(1):43-81 (maio de 1997). Disponível em: http://www.face.ufmg.br/novaeconomia/. Acesso em 18 de novembro de 2012.

SILVA, Iraneide Albuquerque de. O instituto Federal de Educação, Ciência e Tecnologia de Mato Grosso: memória e representações sociais. 2010, 197f. Tese (Doutorado). Universidade do Estado do Rio de Janeiro. Instituto de Psicologia.

SILVA, Sílvio Éder Dias da; CAMARGO, Brigido Vizeu; PADILHA, Maria Itayra. A teoria das representações sociais nas pesquisas da enfermagem brasileira. Rev. bras. enferm., Brasília, v. 64, n. 5, out. 2011 . Disponível em $<$ http://www.scielo.br/scielo.php?script=sci_arttext\&pid=S0034-

$71672011000500022 \& \operatorname{lng}=$ pt\&nrm=iso $>$.

acessos

em 28 out. 2012. http://dx.doi.org/10.1590/S0034-71672011000500022.

SMOLKA, Ana Luiza Bustamante. A memória em questão: uma perspectiva históricocultural. Educ. Soc., Campinas, v. 21, n. 71, jul. 2000 . Disponível em $<$ http://www.scielo.br/scielo.php?script=sci_arttext\&pid=S0101-

$73302000000200008 \& \operatorname{lng}=$ pt\&nrm=iso $>$.

acessos

em 18 nov. 2012. http://dx.doi.org/10.1590/S0101-73302000000200008.

STOETZEL, Jean. Psicologia Social. Tradução de Haydée Camargo Campos. São Paulo: Nacional, 1967.

TRAD, Leny Alves Bonfim. Grupos focais: conceitos, procedimentos e incorporação na pesquisa em saúde coletiva. Physis (UERJ. Impresso), v. 19, p. 10-15, 2009.

UMAÑA, Sandra Araya. Lasrepresentacionessociales: ejes teóricos para sudiscusión. Cuaderno de CienciaSociales 127, FaculdadLatinoamericana de CienciasSociales (FLACSO), Costa Rica, 2002.

VALA, Jorge. Representações Sociais e Psicologia Social do conhecimento quotidiano. In Psicologia Social. Coordenado por Jorge Vala e Maria Benedicta Monteiro. $6{ }^{\text {a }}$ ed. Lisboa: Fundação CalousteGulbenkian, 2004, pp. 457-502. 
VASEN, Juan. Las certezas perdidas: padres y maestros ante losdesafíosdel presente. $1^{\text {o }}$ edição- Buenos Aires: Paidós, 2008, (voces de laeducación).

VEIGA, Luciana; GONDIM, Sônia Maria Guedes. A utilização de métodos qualitativos na Ciência Política e no Marketing Político.Opin. Publica, Campinas, v. 7, n. 1, 2001 - Disponível em <http://www.scielo.br/scielo.php?script=sci_arttext\&pid=S0104$62762001000100001 \& \operatorname{lng}=$ pt\&nrm=iso $>$. acessos em 18 nov. 2012. http://dx.doi.org/10.1590/S0104-62762001000100001.

VIAUD, Jean. Mémoire collective, représentationssocialesetpratiques socials. ReveuConnexions, 2/2003 ( $\mathrm{n}^{\mathrm{o}}$ 80), pp. 13-30. Disponível em: http://www.cairn.info/revue-connexions-2003-2.htm. Acesso em 18 de novembro de 2012.

WAGNER, Adriana et al . Compartilhar tarefas? Papéis e funções de pai e mãe na família contemporânea. Psic.: Teor. e Pesq., Brasília, v. 21, n. 2, ago. 2005 . Disponível em $<$ http://www.scielo.br/scielo.php?script=sci_arttext\&pid=S0102$37722005000200008 \& \operatorname{lng}=$ pt\&nrm=iso $>$. acessos em 05 nov. 2012. http://dx.doi.org/10.1590/S0102-37722005000200008.

ZINCONE, Giovanna. Da sudditti a cittadini. Le viedellostato e leviedellasocietàcivile.Bolonia. Il Mulino,

Notas

\footnotetext{
${ }^{1}$ Universidade Federal da Bahia pampitagoras@ gmail.com

${ }^{2}$ Universidade Estadual do Sudoeste da Bahia lrochamagalhaes@gmail.com
}

Recebido: julho/13 $\quad$ Aprovado: março/14 